\title{
The Raw Materials Summit 2019: connecting innovation in the Raw Materials Sector
}

\author{
Pier Luigi Franceschini ${ }^{1}$. Johan van Boggelen ${ }^{2} \cdot$ Karl Vrancken $^{3}$. Franco Bonollo ${ }^{4}$ - Etienne Bouyer ${ }^{5}$. \\ Raimo Lahtinen ${ }^{6} \cdot$ Jens Gutzmer ${ }^{7} \cdot$ Patrick Nadoll $^{8} \cdot$ Roland Gauss $^{8} \cdot$ Ignacio Calleja ${ }^{8}$
}

Published online: 19 November 2019

(C) The Author(s) 2019

With more than 400 attendants, 65 speakers from Europe and overseas, more than 200 companies participating of which 35 start-ups, the Raw Materials Summit was the first large conference organised by the EIT RawMaterials. The event gathered participants both from the large European Innovation Community working on innovation and education in the raw materials value chain as well as participants from overseas, to present and discuss the latest developments in innovation and new technologies, new ventures and education in the raw materials value chain.

The approach of integrating education, research and industry on which the EIT RawMaterials is based upon was brought to a further level by introducing an additional important component: investors. Through a strategic collaboration with Techtour (https://techtour.com/), the second day of the Raw Materials Summit was dedicated to the Venture Forum, where a selected cohort of start-ups were invited to pitch their innovation in front of venture capital firms and corporate ventures.

Several top-level invited speakers were setting the scene at the start of each day: keynote speeches from Prof. Julian Allwood (University of Cambridge) and Thoralf Hagenbruch (McKinsey) were illustrating the challenges ahead for raw materials. Andreas Klossek (EIT

Pier Luigi Franceschini

pierluigi.franceschini@eitrawmaterials.eu

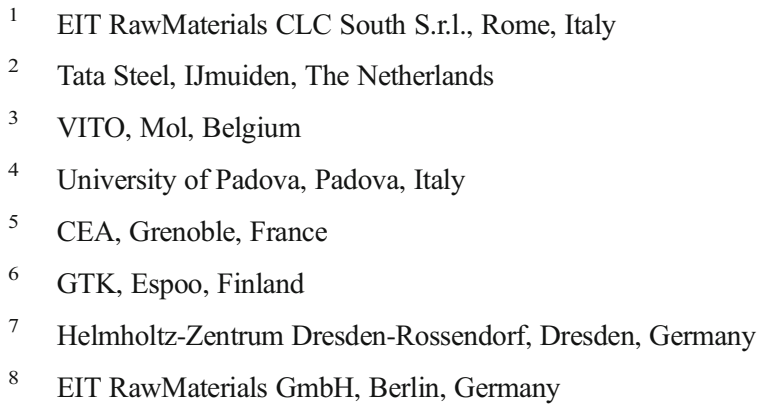

RawMaterials), Jim Totty (Earth Capital) and Stefano Odorizzi (EnginSoft) covered entrepreneurship and new ventures in the raw materials and innovative materials area.

The Summit gave a very innovative perspective also on the new challenges related to education, with emphasis on entrepreneurship: Prof. Thomas M. Cooney from the Technological University Dublin (TU Dublin) talked about "What does it mean to be entrepreneurial?". Rima Dapous (EIT RawMaterials) explained the Raw Materials Academy, through a real-life study, interviewing Denis Gontcharov, President of the EIT RawMaterials Alumni Association, who was formerly enrolled in the academy and now successfully working in the industry.

During the three days of the summit, six technical sessions were running in parallel:

- Resources: Discovery and Beyond: the session was started by John Guven (ICRAG) who delivered an intriguing presentation about a "seismic future" for exploration in Ireland. Massimo Gasparon (EIT RM) presented the new EIT RawMaterials Lighthouse Sustainable Discovery and Supply which aims to highlight the benefits of a strong European raw materials sector. Bo Stensgaard (Blue Jay Mining) talked about the challenges and opportunities in harsh unexplored arctic environments. An intriguing approach on how technology can be used to build trust was presented by Richard Gloaguen (HZDR) and Marie Jose Jurado (CSIC) presented innovative logging tools that will lead the way into the future of exploration and mining

- Deep, Intelligent Mining: Stefan Savonen (LKAB) illustrated the industry's viewpoint on sustainable mining and processing. Additional industrial perspective on automation in mining equipment was provided by Åsa Gabrielsson (EPIROC). Irene Benito Rodriguez (EIT RawMaterials) showed the opportunities of satellite 
Earth Observation as a tool to boost raw materials extraction and environmental impact monitoring. A fresh perspective on new education tools provided by Infomine for the extractive industries was given by Marc Borbas (Infomine). Artur Zakirov (RISE) and Eija Saari (OUTOTEC) presented two successful projects of the EIT RawMaterials, SERENE and IRIS, addressing respectively water management and safety in mines.

- Minerals Processing and Materials Recycling: Increasing resource, energy and water efficiency during raw materials beneficiation: The session started with a talk by Prof. Peter Hayes (University of Queensland), setting the scene and illustrating the issue of the deteriorating quality of ores. Dealing with these challenges provides opportunities for innovation. Jean-Michel Milazzo (ERAMET Research) presented the GO-4-0 project, which aims to turn waste products into valuable alloys. Christian Binder (Outotec) presented MONICALC, another EIT RawMaterials' project showing large improvements in energy use in kaoline calcination. Three commercialised technologies resulted from this project. Phil Newman from Anglo American presented the METGROW and ITERAMS projects, these were examples of Horizon 2020 projects, featuring topics aligning with the EIT RawMaterials objectives. The final presentation was by Darina Styriaková from a start-up called Ekolive, which originates from the EIT RawMaterials project BIOLEACH. It uses microbes to recover metals or clean minerals from specific contaminants.

- Advanced Materials-Enablers for Disruptive Innovation: Lightweight design, additive manufacturing, design of new alloys: The first presentation (Ph. Jacques, EMIRI) was an overview of European initiatives that will contribute to a carbon neutral society; a focus on the battery initiative has been presented among other European instruments. In addition, some details about the future European framework programme (Horizon Europe) has been given in order to show where the material activities will be put within the three pillars. Prof. M. Vedani, Politecnico Milano, focused on the way to (better) design alloys well suited for additive manufacturing processes, giving examples from aluminium alloys as well as from stainless steel. Dr. T. Madiberk (Skeleton) presentsed energy storage through supercapacitors. The SKELETON approach is to use curved graphene as active materials that enhance the energy density capacity in order to build full integrated storage system. Dr. M. Glotin (Arkema) was directly linked with an EIT RM ongoing upscaling project called SUPERSMART. The approach based on printed electronic on paper is aiming to embed sensors for making smart products with low environmental impact (recyclable). Prof. O. Gutfleisch (TU Darmstadt) showed how magnetic materials are useful in numerous key technologies. Based on the magnetocaloric effect (MCE), the targeted application is for cooling system based on magnetic refrigeration. Materials exhibiting such property could necessitate Critical Raw Materials (CRM); thus the presentation addressed some ways to overcome this issue (through substitution or by using recycled magnets).

- Materials for Future Mobility: Challenges for raw materials and new materials for future mobility, including batteries and magnets. Daniele Pullini, FIAT Research Centre, described the size and status of the EU automotive sector, with 2.5 million people currently involved in the manufacturing of motor vehicles (i.e. $8.2 \%$ of the EU employment in manufacturing). New forms of sustainable mobility are fundamental in the transition towards a Green Economy. Michel Glotin (Arkema) reviewed opportunities and challenges for composites in automotive, in competition also with high strength steel, aluminium and magnesium for steel substitution. Claudio Mus (Endurance Overseas) evidenced that Lightweight materials like aluminium are currently in high demand for electric vehicles as low weight equals longer range or a reduction of the battery cost. Erik Svedlund (Epiroc) presented the Mining industry as one of the big winners in the transformation to zero emission and electrification. Relevant examples of underground mining equipment addressed to battery electrification have been shown. Maria Åstrand (Northvolt) discussed about the global political, environmental and technological trends driving the demand towards a rapid increase in lithiumion batteries, turning it to a strategically important domain for both industry and society. Guillame Claude (CEA) described the ALIM project, supporting commercialization of critical raw material (CRM)-free innovative battery solutions, by mastering the production process of extra-thin lithium electrodes and boosting the performances of current cells, by use of rolling mills to produce thin electrodes.

- Resource Efficiency Cities: Urban and landfill mining, materials flow analysis, circular economy-The session contained two more general presentations from Nikolai Jacobi (ICLEI) regarding general aspects related to resource efficient and circular cities and a second one by Markus Reuter (Helmholtz) regarding metallurgical processing and circularity. This was followed by three more technology-specific presentations from Yiannis Pontikes (Leuven university) related to construction materials and industrial-urban symbiosis (The RECOVER project funded by EIT Rawmaterials), a second one by Martin Schlummer on displays recycling (Display project funded by EIT Rawmaterials) and a third one for magnets recovery by Alex Bevan from Urban Mining Company (USA). 
The RM Summit featured also satellite workshops: the CERA project, an innovative raw material certification platform supported by EIT RawMaterials and coordinated by the German company DMT, held a workshop to discuss progresses and way forward. Outotec organised a workshop with students on "Possibilities for business - service-based entrepreneurship". The SUPRIM project held a workshop entitled "Practitioner stakeholder workshop on an enhanced LCA methodology for Resources". The EIT RawMaterials Alumni organisation organised a challenge for industries entitled "Engage \& compete with EIT RawMaterials Alumni in a survival challenge".

The Raw Materials Summit showed that it is a great time to innovate in the RM sector, and that raw materials play a central role in the road to meet the ambitious goals of reducing $\mathrm{CO}_{2}$ emissions and meet the best mitigations scenarios.
In 2020, the second edition of the Raw Materials Summit will take place once again in Berlin from the 18th to the 20th of May, with a similar format, aiming at increasing the community and ecosystem engagement in the programme and with higher involvement of industries and policy makers. More information will be available soon on www. eitrawmaterials.eu.We are looking forward to see you on 1820 May 2020 at the Raw Materials Summit 2020!

Open Access This article is distributed under the terms of the Creative Commons Attribution 4.0 International License (http:// creativecommons.org/licenses/by/4.0/), which permits unrestricted use, distribution, and reproduction in any medium, provided you give appropriate credit to the original author(s) and the source, provide a link to the Creative Commons license, and indicate if changes were made. 